\title{
Profile of Amputations in National Orthopaedic Hospital, Dala, Kano
}

\author{
Abdurrahman Alhaji Mamuda1, Muhammad Nuhu Salihu², \\ Muhammad Kabir Abubakar1, Kabir Musa Adamu1, Mustapha Ibrahim1, \\ Muhammad Ujudud Musa ${ }^{3 *}$ \\ ${ }^{1}$ Aminu Kano Teaching Hospital, Kano, Nigeria \\ ${ }^{2}$ National Orthopaedic Hospital Dala, Kano, Nigeria \\ ${ }^{3}$ Surgery Department Aminu Kano Teaching Hospital, Kano, Nigeria \\ Email: dattijongoggo@yahoo.com, mohammedsalihu@yahoo.com, emkeabubakar@gmail.com, \\ mdrkabir@yahoo.com, mustyibro90@gmail.com, ujudud@gmail.com
}

Received 29 May 2014; revised 15 July 2014; accepted 29 July 2014

Copyright (C) 2014 by authors and Scientific Research Publishing Inc.

This work is licensed under the Creative Commons Attribution International License (CC BY).

http://creativecommons.org/licenses/by/4.0/

(c) (i) Open Access

\section{Abstract}

Introduction: Amputation is the removal of a body part through a bone, while disarticulation is a removal of a part through a joint. This common procedure has different causes depending on the geographical locations and cultural practices. These ranges from dead body part to malignancy. Our study focused on the profile of the amputees including the biodata, causes and the financial consequences of the procedure. Material and Methods: The case notes of all patients who had amputation from 1998-2012 (15 years) were collected and the biodata, intra-operative diagnosis, parts amputated and duration of hospital stay were retrospectively analysed. Results: One hundred and ninety six patients had various types of amputations for the duration of our study. $159(81.12 \%)$ were males while $37(18.88 \%)$ were females. $68(34.69 \%)$ patients had below knee amputation. 54 $(27.55 \%)$ had above knee amputation. $27(13.78 \%)$ had above elbow amputation. $18(9.18 \%)$ patients had below elbow amputation, while $30(15.30 \%)$ patients had other forms of amputations. The highest number of amputees (72 patients) was within the age range of $21-30 \mathrm{yr}$ and the least number (5 patients) was within the age range of 51 - $60 \mathrm{yr}$. The highest number of amputation (71 patients) was due to complications from by traditional bone setters intervention. Conclusion: In our study, we found that most cases were males with a mean age of 35 years and majority $(34.69 \%)$ had below knee amputation, and that most cases suffered vascular occlusion leading to gangrene.

\section{Keywords}

\section{BKA (Below Knee Amputation), AKA (Above Knee Amputation)}

\footnotetext{
${ }^{*}$ Corresponding author.
}

How to cite this paper: Mamuda, A.A., Salihu, M.N., Abubakar, M.K., Adamu, K.M., Ibrahim, M. and Musa, M.U. (2014) Profile of Amputations in National Orthopaedic Hospital, Dala, Kano. Open Journal of Orthopedics, 4, 200-204. 


\section{Introduction}

Amputation is the removal of a part of a body through a bone while disarticulation is the removal of a part through a joint. It is a common procedure undertaken by surgeons worldwide. There were about 1.6 million amputees in 2005 in the United State of America, and the reasons range from a dead body part, a dangerous body part or nuisance from a body part. This can be further broken into individual causes such as trauma, vascular injuries, infections, neoplasia etc. [1] [2].

The reasons for the amputations also vary in different parts of the world and also among different regions of same nation and this may be due to some cultural practices or prevalent disease conditions [3].

We therefore undertake to study the profile of amputations in our centre Visa-Vis amputations, the parts affected, duration of hospital stay as well as the morbidity suffered from the procedure.

Indications of amputation:

1) Loss of viability secondary to reconstructive ischemia

2) Trauma

3) Tumour

4) Extensive infection which does not respond to conservative measures

Two third of amputations in the western societies are due to peripheral vascular diseases and commonly are the above knee and below knee amputations [4].

At each level, the operative procedure and post operative management are directed at achieving primary healing a painless stump that will withstand the pressure of prosthesis and relatively unrestricted for ambulation.

Selection of level: Several factors attributed to the selection of levels of amputation which includes the indication, available stump, prosthesis fixation and cosmetics required. In tumours, wide local excision is done while in peripheral vascular diseases the extend of healthy tissues are considered.

Above Knee Amputation (AKA) expends about energy to ambulate compared to Below Knee Amputation (BKA), while the overall mortality for amputations performed for isolated tumours, traumas or infections were less than 3\% [5]

Extremity re-plantation: successful hand re-implantation was registered in 1963. Microvascular techniques result in increasing success. A summary of the experiences from China, US and Switzerland showed that one third had functional recovery and one third was fair to poor results [6].

Studies showed that up to four percent of good function follows above elbow amputation, proximal forearm had $0 \%-70 \%$, while distal forearm recorded 50\% - 83\%, wrist in 25\% - 80\%, palm was seen in $25 \%-70 \%$, thumb had 32\% - 90\%, while proximal PIP joint was seen in 70\% and distal to PIP was recorded in 100\% [1] [4].

Guillotine injuries have higher degree of success at re-implantation compared to crush injuries. Also if duration of anoxia is less than 20 hours, the success rate is higher [4] [5].

The essential structures of the dismembered extremity must be intact and the severed limb reasonably well preserved if re-implantation is attempted [5].

\section{Materials and Method}

The case files of all patients who had amputations in the National Orthopeadic Hospital Dala, Kano Nigeria between 1998-2012 were retrospectively analyzed. After a literature search was done a proforma was designed to extract the discrete and non discrete information of the patients in the case folders. Data on age, sex, intra-operative diagnosis, part amputated, duration of hospital stay and the morbidity suffered in the course of treatment were analyzed, and the results were compared with other studies. Ethical clearance was obtained from the hospital research and ethics committee and there was no research grant obtained for this study.

\section{Results}

A total of 196 patients were studied, including 159 males and 37 females with a male to female ratio of 4.3:1. Their age ranged from 5 years to 67 years with the median age of 36 years.

\section{Discussion}

Amputation is the removal of a body part through a bone is a common orthopaedic procedure with different outcome depending on the indication, presentation and the type of amputation done. 
In our study, we found a total of 196 cases who had amputation in our centre within the period of 15 years. Out of which, 159 (81.12\%) were males and 37 (18.88\%) were females with a male to female ratio of 4.3:1 which differs from findings by Lcle, A. et al., Chalya, P.L. et al., Dos Santos Taveres, D.M. and Enweluzo, G.O. who discovered a male to female ratio of 1.2 - 1.7:1 in different centres across the world [7]-[10] (Figure 1).

We found a mean age of 35 years which is slightly higher than the findings by Chalya PL in Costa Rica, who found a mean of 54.2 years and Enweluzo, G.O. in Lagos who found a mean age of 43 years [6] [9].

68 (31.69\%) out of 196 patients had below knee amputations followed by 54 (27.55\%) patients who had above knee amputations, while 27 (13.78\%) had above elbow amputations. This compares favourably with the findings by Lacle, A., Chalya, P.L. \& Enweluzo, G.O. [6] [7] [9] (Figure 2).

Also we discovered that 66 patients had left sided lower limb amputations followed by 53 patients who had had right sided upper limb amputations; and only 3 patients had a bilateral amputations; and previous writings studied were silent on side affected.

In addition, we also discovered that most of our cases were secondary to traditional bone setters splintage (tight occlusions of the blood supply by traditional splints leading to gangrene) accounting for 71 cases (36.22\%) followed by road traffic accidents in 36 cases $(18.37 \%)$ and the others. This is contrary to the findings by Lacle A. \& Enweluzo who found diabetic foot to be the commonest cause and Fagundes who found vascular injury to be the commonest cause [6] [7] [11].

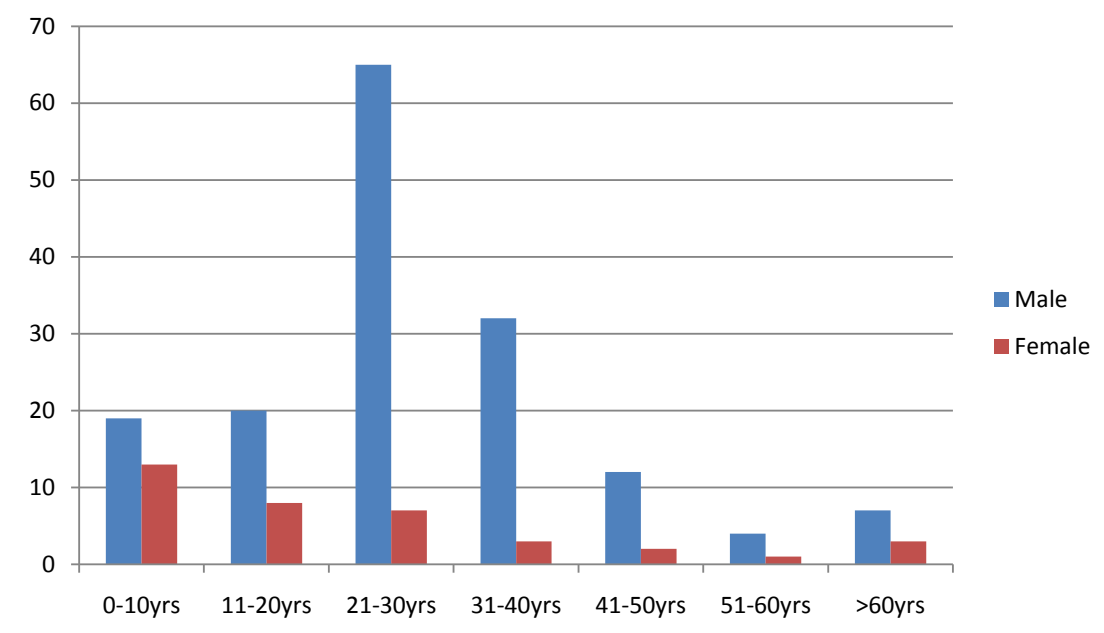

Figure 1. Histographic presentation of age distribution.

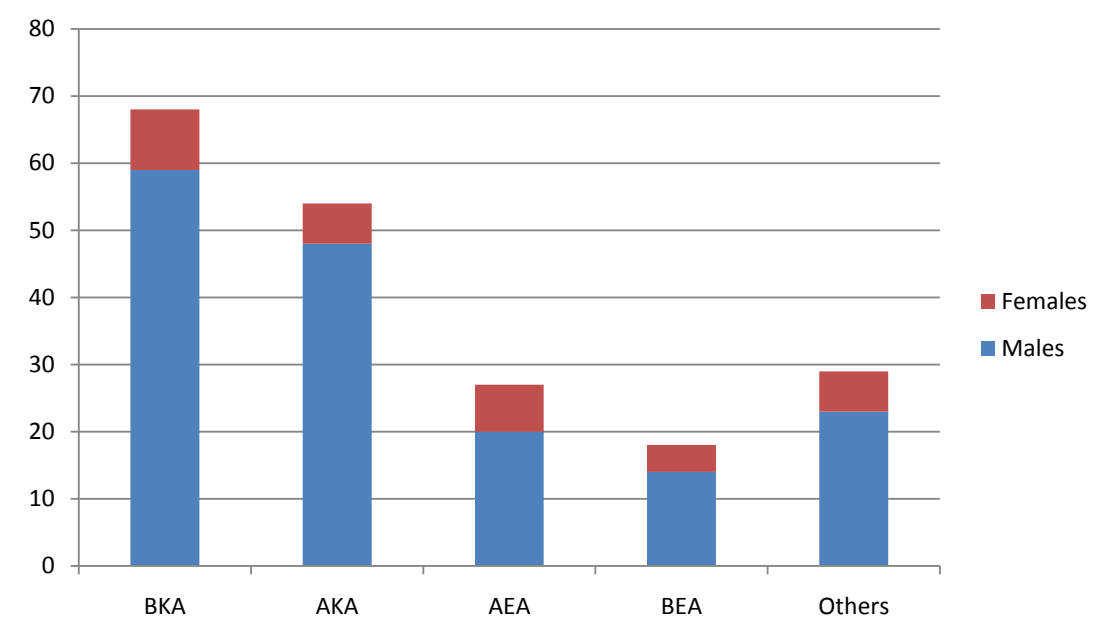

Figure 2. Shows distribution of their level of amputation: Below Knee Amputation (BKA), Above Knee Amputation (AKA), Above Elbow Amputation (AEA), Below Elbow Amputation (BEA). 
The range of hospital stay was between 5 days to 7 months with an average of 30 days in most patients and this differs from the findings by Chaya, P.L. who discovered a range of $18-28$ days with an average of 36.24 days [7] (Figure 3).

158 (80.61\%) out of 196 patients who had amputations within the period were discharged and only 3 (1.53\%) suffered some morbidity with only $1(0.51 \%)$ mortality while the remaining were either referred in the course of treatment or discharged themselves against medical advice which is contrary to the findings by Chalya, P.L. who found a mortality rate of 1.325 and Enweluzo, G.O. who found a mortality rate of 11.8\% [7] [9] (Figure 4).

\section{Conclusions}

Above findings have indicated that most of our cases were males with a mean age of 35 years and most patients had a below knee amputations in most instances left sided which may be explained by left sided driving instead of right sided steering in other communities.

Most cases suffered a secondary excessive occlusion of the vascular supply leading to gangrene and ultimate amputation and this is avoidable through massive public enlightment campaign.

In Africa and other part of the developing world, the problem of Traditional Bone Setters (TBA) intervention is serious one which needs an urgent attention by the authorities.

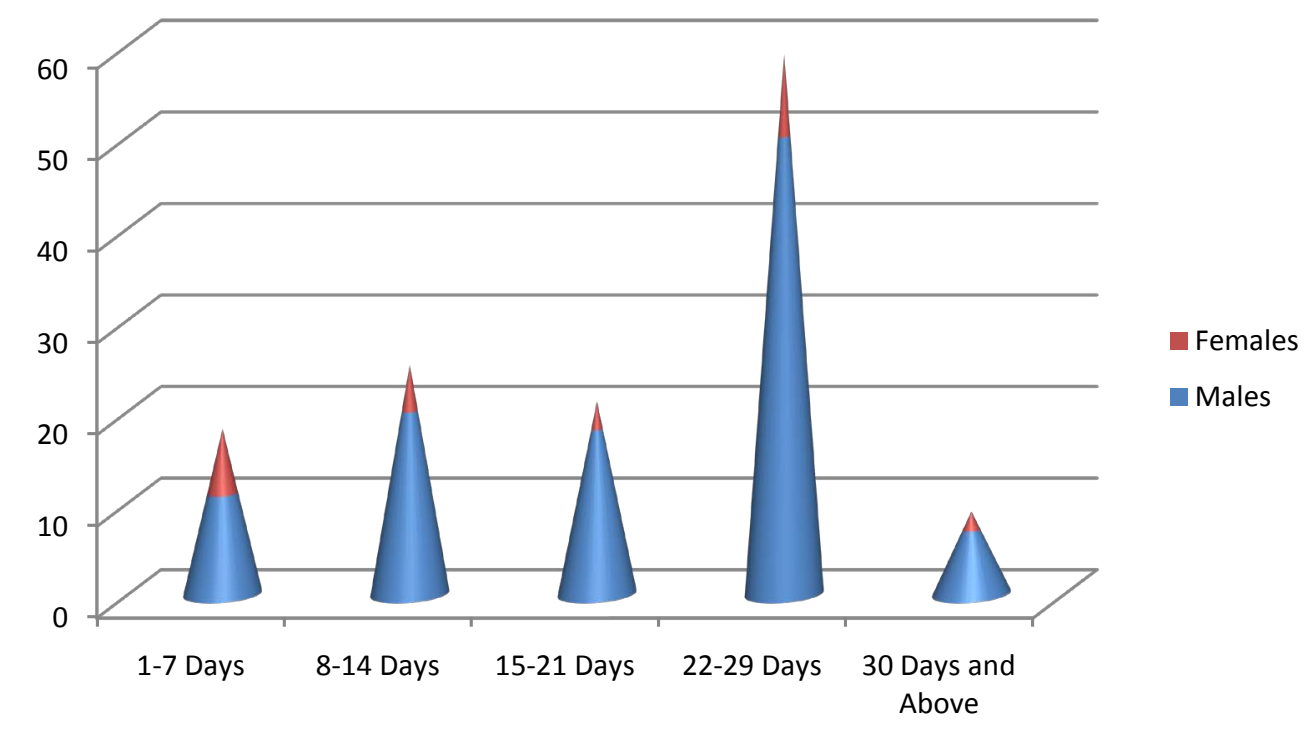

Figure 3. It shows distribution by hospital stay.

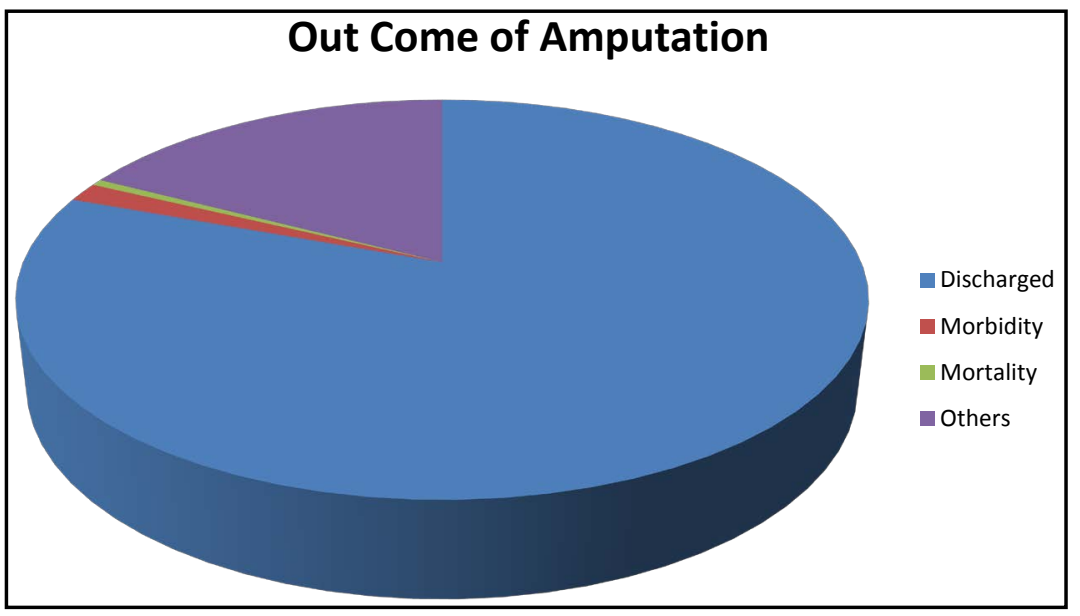

Figure 4. It shows distribution by outcome. 


\section{Completing Interest}

The authors declare that they have no completing interests.

\section{Perspective}

To see how we can reduce hospital stay and reduce the avoidable amputations from Traditional Bone Setters (TBS) by:

- Doing primary amputations at appropriate levels

- Ensuring aggressive debridement and wound care

- Using the appropriate antimicrobial agents

- Prompt rehabilitation

\section{Authors Contributions}

Dr. Mamuda, A.A. carried out: conception of the paper, drafting of manuscript, design of the study, analysis of data and interpretation of data and revising the manuscript.

Dr. Salihu, N.M. carried out: drafting of manuscript, acquisition of data, analysis and interpretation of data.

Dr. Abubakar, M.K. carried out: acquisition of data, design of study and revising the manuscript.

Dr. Kabir, M.A. carried out: drafting of manuscript, conception and design of study and revising the manuscript.

Dr. Mustapha, I. carried out data acquisition, revising the manuscript and analysis of data.

Dr. Ujudud, M.M. carried out drafting of manuscript, design of study, acquisition of data, analysis and interpretation of data and revising the manuscript.

\section{References}

[1] Burnes, R.W. and Thornwell, B. (1981) Prediction of Amputation Wound Healing, Roles of Doppler Ultrasound and Digit Photoplethysmosgraphy. Archives of Surgery, 116, 80-83. http://dx.doi.org/10.1001/archsurg.1981.01380130056013

[2] Murdoch, G. and Wilson Jr., A.B., et al. (1996) Amputation: Surgical Practice and Patient Management. ButterworthHeinemann Medical, St Louis.

[3] Burgess, E.M. and Romano, R.L. (1965) Immediate Post Surgical Prosthesis Fitting. Bulletin of Prosthetics Research, 10.

[4] Clyne, C.A.C. (1991) Selection of Level of Amputation in Patient in the Severe Prepheral Vascular Disease. Archive of Annals of The Royal College of Surgeons of England, 73.

[5] Gregory Dean, A. (1991) Amputation Statistics and Trends. Annals of the Royal College of Surgeons of England, 73.

[6] Weic, A., Meyer, V.E., et al. (1981) Presentation Indication and Contraindication for Replantation as Reflected by Long Term Functional Results. Orthopedic Clinics of North America, 12.

[7] Lacle, A., et al. (2012) Diabetes Related Lower Extermity Amputation, Incidence and Risk Factors. Revista Panamericana de Salud Pública, 32, 192-198. http://dx.doi.org/10.1590/S1020-49892012000900004

[8] Chalya, P.L., et al. (2011) Surgical Management of DM Foot Ulcers, a Tanzanian University Hospital Experience. BMC Research Notes, 24, 365.

[9] Dos Santos Taveres, D.M., et al. (2009) Profile of Patients Submitted to Amputation Related to DM. Revista Brasileira de Enfermagem, 62, 825-830.

[10] Enweluzo, G.O., et al. (2010) Profile of Amputations in Lagos University Teaching Hospital Nigeria. Nigerian Quarterly Journal of Hospital Medicine, 20, 205-208.

[11] Fagundes, C., et al. (2005) Prognostic Factors for Amputation or Death in Patients Submitted to a Vascular Surgery for Acute Limb Ischeamia. Vascular Health and Risk Management, 1, 345-349. 
Scientific Research Publishing (SCIRP) is one of the largest Open Access journal publishers. It is currently publishing more than 200 open access, online, peer-reviewed journals covering a wide range of academic disciplines. SCIRP serves the worldwide academic communities and contributes to the progress and application of science with its publication.

Other selected journals from SCIRP are listed as below. Submit your manuscript to us via either submit@scirp.org or Online Submission Portal.
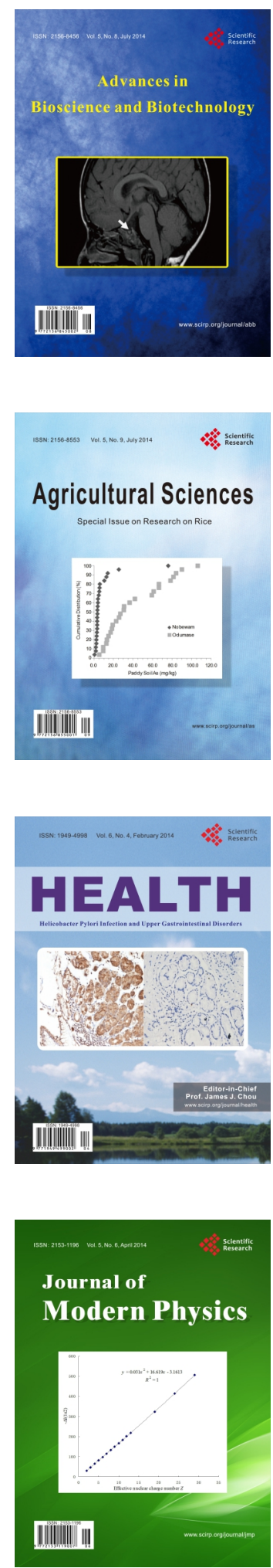
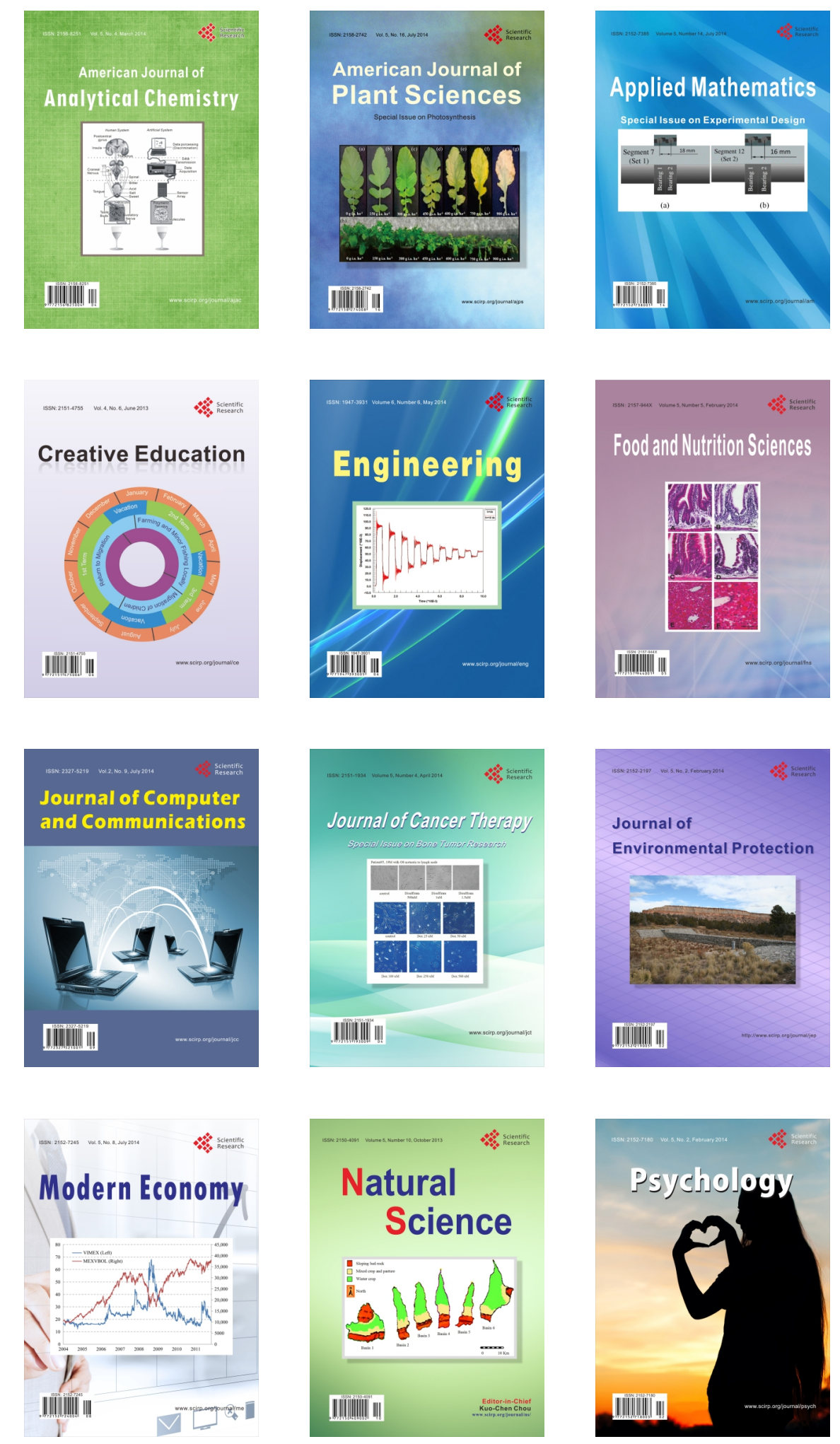